\title{
Research and Some Operation Suggestions on the Relationship Between Project and Sub-Project in R \& D Project
}

\author{
Wei Tang ${ }^{1.2}$ \\ ${ }^{1}$ Hohai University, Jiangsu, China \\ ${ }^{2}$ Nanjing xiaozhuang University, Jiangsu, China
}

\begin{abstract}
With the increasing competition in the market and the increasing complexity of the products, more and more enterprises are trying to use the project management to complete the relatively complex tasks. How to manage the hierarchical project effectively, which is related to the effective implementation of the strategic objectives of the enterprise. Taking a high-tech company as an example, this paper analyzes the common problems of project management, and puts forward the concrete improvement ideas. This management optimization idea has a wide range of reference for other enterprises.
\end{abstract}

\section{Introduction}

With the aggravation of the market competition, product complexity is increasing. Project management approach is commonly used in more and more product development. All activities will be considered as a project management. If the size of the product development task is very complex, the first action is setting up the corresponding portfolio management, and the second is setting up the project group in the project portfolio, the third is setting up the project in the project group. Project management is not only to help enterprises to solve complex research and development issues, but also to increase the difficulty of the management of enterprises, and put forward new challenges.

How to regulate the behavior of enterprise management and the staff by hierarchical project management and portfolio management? Practice and theory circles are working hard to clarify the relationship between project activities. All this is to promote the realization of the enterprise's overall strategic objectives.

They have different standards for different companies to divide the project and sub-project. When we can take the project and sub-project as a whole, it follows the general rules of project management. This paper focuses on the relationship between the project and its sub projects, through a high-tech company project management problem, to seek the improvement of project management.

\section{Basic theories on project sub-project management}

\subsection{The level of the project and the intrinsic relationship}

According to the different strategic objectives, current industry divides different levels to manage, such as: project portfolio, project group, single project, sub project, etc.

PMBOK (Project Management Body Of Knowledge) proposed: above the level of project, there are Portfolio, program and so on; the project portfolio is composed of a series of programs, program is composed of a number of projects. Refer to the above rules, below the level of project, we can set up sub project; a project can be composed of several sub projects, and then launch a series of activities around the WBS decomposition of the various specific goals.

The relationship between program, project, sub-project, for different levels of management, may be WBS (Work Breakdown Structure) in different decomposition level or the relationship between scope and activities. Therefore, the division is the need for project hierarchical management. We firstly defined the meaning of Project, so as to define the corresponding Program and Sub project, and then define the boundaries of the scope and activities in the project naturally.

In addition, in the PMI (Management Institute Project) of the WBS standard practice, it focuses on how to establish WBS and the degree of WBS decomposition. Through the decomposition of the standard, it can be seen to what extent is appropriate, according to the management of the underlying content (Manageable) to the management. The main content from the complexity, cost, time, resources and risks should be considered. This should also be taken into account with the relationship between WBS and organizational structure. These considerations of management can also help different levels of management to consider the depth of project management. 


\subsection{The project group and the management of two level project}

Project management is a hierarchical management, the project group, project, sub-project can be seen as the three layer management structure:

Project management is a relatively new concept. As an extension of the concept of the project, its meaning is not yet finally unified. Different scholars, organizations have different understanding of it. PMI proposed project is a group of interrelated activities and need to coordinate the management of the project based on the link of project. The characteristic of the project group is composed of a number of projects, which are composed of a number of simultaneous or overlapping parts of the project. These items have a certain logical relationship, or they have no logical relationship, but they have similar characteristics. The project group is managed as a whole, but each project operates independently .In general, group project will not interfere in the internal management of a project, but the delay of a project may affect another project.

The project is the foundation of the project group and the project combination. The whole project is a project main body, can have a number of sub projects, in accordance with the standards of the project management norms.

Sub-project is the minimum management unit of project management. In order to facilitate the overall project management, according to the contents of the work and the different participants, according to the professional group we can set up many sub-projects. Sub-project operation is relatively independent; the parent project can also interfere with the operation of the sub-project.

Project group, project, sub-project can be transformed into each other according to the management of the different particles. If the project size is larger, the decomposition level is more.

\section{The problems existing in the project management}

\subsection{Process and specification}

When sub-project is set up, the project management does not know about it; when the project makes some adjustment, sub-project can't get the notice in time. The decision making process of project adjustment is lack of process and specification. Sub-project needs to serve several projects, but the specification and process is not enough to support project information exchange.

\subsection{Resource management}

Due to the project resources can't be shared, project resources aren't unified budget, resulting in repeated investment and low efficiency. Sub-project from multiple management, it is difficult to carry out resources of coordination.

It is not easy to reach the goal through the trading system of resources.

\subsection{Assessment and incentives}

Sub-project award should be determined by the parent project to assign, but IT system can't support. Subprojects working hours can't get data automatically. It will spend a lot of manpower and time to obtain relatively accurate data. So its process is often simplified.

\section{The improvement measures of two-level project management}

\subsection{Issue some regulations to strengthen the project management}

In the light of the exposure of project management problems of a high-tech company, The company project management office introduce series of related systems to promote and project management rules based on a large amount of basic research, combined with the practice experience. These rules are as follows:

\subsection{1 "Father-son relationship management norms in R\&D project"}

The specification in the field of project management carries out the provisions, including these areas such as decisionmaking, change, monitoring, and knot items, In the field of resource management, the project and sub-project 's budget, resource transactions, the actual workload has also been clearly defined. In the field of assessment, some related issues are also explained with the project performance evaluation, project award and cohesion award.

\subsection{2 "R\&D project establishment management procedures"}


This specification relates to the requirements of the project of two-level -project. The process of the project is clearly defined, and the requirement of input and output of the project is put forward.

\subsection{3 "R\&D project management"}

The specification involves the management of parent-child project management requirements; product development team may set up two level projects in accordance with the product development process and the characteristics of the project, and to develop a two level plan. First level plan is for the product development project, product manager is for the person in charge; the second level is for the professional group of sub projects, the professional group representative is the person in charge of the corresponding sub project.

\subsection{4 "General requirements for product development work"}

In the definition of typical project life cycle, the relationship between project and sub-project is related to the project. Product development should adopt the project management mode; all activities of the product development are treated as a project to manage. In order to facilitate the overall project management, the professional group project can be further divided into a number of project management according to the content of the work and personnel involved in the establishment of different projects, according to the professional group. For example, after the completion of system design, they will be divided into hardware, software sub project and structure sub project etc.

\subsection{Transform the IT system to support the two-level-project management}

In addition to publishing the corresponding standard, training and publicizing, the company also invested considerable power in improving the current project management IT supporting system; its aim is to standard project management activities using the electronic process. All the management activities are all based on E-business. The system supports the subsequent resource allocation, assessment incentives and so on.

\subsubsection{Set project}

In the project management aspect, adjusting project process, the project management system is electronic transformed to support the two-level -project. The requirements of two-level-project management are as follows:

Father and son project should be set up in the project management system after the formal entry into force; the project should be associated with the project's parent project. Before the end of the parent project it does not allow the following new project establishment.

The specific timing of sub project can be flexible according to the characteristics of the sub project: project proposal started within two weeks after the completion of the father project; for test equipment, it is recommended to start to collect them after reviewing the parent project system design.

According to the parent project target, the parent project manager decompose the sub project work scope and objectives, and assign the sub- project manager to prepare the R\$D task book. Sub projects directly follow the parent project follow-up phase information (including the stage name, the stage start and end time). The examination and approval of the project shall include the parent project manager.

\subsubsection{Decision-making}

In the decision management aspect, according to the parent and son project management decision-making process, The company carried out the E-system to support parent-son project decision-making. Parent-son project decision-making requirements are as follows:

Sub-project has no need to set up a separate of conventional decision points, but together with the conventional decision-making. However, according to the actual situation of the sub project may be held in accordance with the actual situation of the interim decision, the provisional decision team members should include the parent project manager.

\subsubsection{Adjust}

In the project change aspect, according to the two level project change process, the project team carried out electronic transformation to support the change of two-level project management. The request for a change in a son project is as follows:

Parent project change: no matter what is the impact to the sub-project, the change should be notified to the sub project manager. If there is an impact on the sub project, the change of child project should take effect under the approval of the change of the parent project. 
Sub- project changes: no matter what is the influence on the parent project, the change of sub-project should be approved by the parent project manager, if the project has an impact on the parent, should wait for the approval by the parent project. After the approval, the sub-project may be changed.

\subsubsection{Monitoring}

In the project supervision and management aspect, according to the two-level -project monitoring process, the project management team carried out the E-system to support the two-level-project monitoring. And project monitoring requirements are as follows: the project manager should report the progress regularly to the parent project manager project, including project weekly report, monthly report, milestone report and so on.

\subsubsection{Project closing}

During the application of knot, according to the two level project's knot procedure, The company carried out the electronic transformation to support the two level project knot. The requirements of the parent and child items are as follows: only when the parent project is under the knot, the parent has the ability to get the knot.

\subsubsection{Assessment and motivation}

In the assessment and motivation aspect, according to the two-level-project process, The company carried out electronic system to support two level project incentives. Bonus is needed to reserve for sub-project separately, the team member of sub-project declare the bonus according to milestone, but the details and results of bonus distribution of sub-project members should be transparent to the sub-project manager.

When the project milestone bonus amount is calculated, the sum of the manpower budget of two-lever-project should be adopted.

\section{The conclusion}

There are many similarities between two-level-project and project group management. In some conditions, the two level project and project group can be transformed into each other. In the project management, the company needs to define the project group, the parent project, sub project for they have different particle size. The project should have a clear classification of the particle size standards, and carry out the necessary project portfolio management and hierarchical management.

The project portfolio management for R \& $\mathrm{D}$ project is of great strategic significance, such as some large, comprehensive or multi-unit cooperative project, Company executives or senior supervisor is responsible for the execution. In the management mode, it is mainly to establish the mode of the project portfolio management office, which mainly has the overall planning and coordination management of the resources. Project portfolio management office should submit relevant definition of the organizational structure, role definition, document templates and other related documents.

This paper puts forward some suggestions for making specification, process management and standardizes the process in E tools, managers need to utilize the project management theory to make some management innovations and optimize the project management activities. Only we continuously promote the project operating level of the enterprise, we can improve the market competitiveness of enterprises.

\section{References}

1. Fricke SE, Shenhar AJ. Managing multiple engineering projects in a manufacturing support environment. HE Transactions on Engineering Management 2000; 47(2)

2. Jennifer Bates, PLANNING \& SCHEDULING -DEVELOPING ACTIVITY LOGIC. AACE International, Inc. AACE International Recommended Practices, March 26, 2004

3. Gregory t. Hogan, Effective Work Breakdown Structures, Mechanical industry press , 2005-07

4. Shelly A. Brotherton, Robert T. Fried, Eric S. Norman, Applying the Work Breakdown Structure to the Project Management Lifecycle, PMI Global Congress Proceedings@, 2008

5. WAN Li ,CHEN Xing-pan, LIU Qing-hua, Project management oriented to product-development process in PDM .COMPUTER INTEGRATED MANUFACTURING SYSTEMS

6. GUI Wei-min, YANG Nai-ding, JIANG Ji-jiao, Enterprise Strategic Project Management, CHINA SOFT SCIENCE, 2004(5)

7. Li Zhe, Zhou Huadong, Li Yan, Experience and Inspiration from Foreign Professional S\&T Program Management Agency: An Example of DLR-PMA. Forum on Science and Technology in China, 2015 (1) 
8. Paul O. Roberts. Supply Chain Management: New Directions for Developing Economies. World Bank Report. 2001. 